\title{
Intervenção fisioterapêutica em uma criança com coronavírus em um hospital de referência: relato de caso
}

\author{
Physiotherapeutic intervention in a child with \\ coronavirus in a reference hospital: case report
}

\section{Jamile Silva de Oliveira' ${ }^{1}$ Isis Nunes Veiga ${ }^{2}$ (1) Carolina Santos Mota ${ }^{3}$ (1)}

\author{
'Autora para correspondência. Instituto Couto Maia (Salvador). Bahia, Brasil. milefisioterapia@hotmail.com \\ ${ }^{2}$ Centro Universitário Unifas - Unime e Dom Pedro II (Salvador). Bahia, Brasil. isisveiga@hotmail.com \\ ${ }^{3}$ Centro Universitário Dom Pedro II (Salvador). Bahia, Brasil. carolinamota097@gmail.com
}

RESUMO I INTRODUÇÃO: Apesar de apresentar-se em menor frequência, os casos graves do COVID-19 podem também afetar a população pediátrica. Considerando este fato, constata-se a eficácia da fisioterapia, que consiste numa especialidade terapêutica que exerce papel fundamental na prevenção e tratamento de complicações pulmonares. OBJETIVO: Descrever o quadro clínico de uma criança portadora de Cardiopatia Congênita com Coronavírus positivo e abordar a atuação fisioterapêutica pediátrica. MATERIAIS E MÉTODOS: Trata-se de um relato de caso de uma paciente de 5 anos e 11 meses de idade, com diagnóstico antecedente de Cardiopatia Congênita dos tipos: Persistência do Canal Arterial e Comunicação Interventricular. A paciente foi admitida na Unidade de Terapia Intensiva Pediátrica do Instituto Couto Maia apresentando-se taquicárdica, taquipneica, com saturação periférica de oxigênio (SpO2) de $85 \%$ em uso de máscara não reinalante, com aumento do trabalho ventilatório e tosse produtiva ao comando verbal. Ao realizar RT-PCR obteve resultado positivo para o Coronavírus. RESULTADOS: Os dados coletados por meio de análise de prontuário e observação clínica da paciente demonstraram que a intervenção fisioterapêutica, quando contou com técnicas de higiene brônquica, manobras reexpansivas e condutas motoras ativas, contribuiu com a evolução clínica da paciente evidenciando melhora na SpO2 e no desconforto ventilatório. CONCLUSÃO: As intervenções fisioterapêuticas aplicadas a este perfil de paciente, demonstraram resultados positivos no que diz respeito a melhora das trocas gasosas e desconforto respiratório, bem como parece influenciar a redução do risco de declínio funcional.

PALAVRAS-CHAVE: Fisioterapia. Terapia respiratória. Infecções por Coronavirus. Pediatria.
ABSTRACT | INTRODUCTION: Despite presenting less frequently, severe cases of COVID-19 can also affect the pediatric population. Considering this fact, the effectiveness of physiotherapy is evidenced, which consists of a therapeutic specialty that plays a fundamental role in the prevention and treatment of pulmonary complications. OBJECTIVE: To describe the clinical picture of a child with Congenital Heart Disease with positive Coronavirus and to address pediatric physiotherapeutic activities. MATERIALS AND METHODS: This is a case report of a 5-year 11-month-old patient with a previous diagnosis of Congenital Heart Disease of the following types: Artery Channel Persistence and Interventricular Communication. The patient was admitted to the Pediatric Intensive Care Unit of the Couto Maia Institute, presenting tachycardia, tachypnea, with peripheral oxygen saturation (SpO2) of $85 \%$ using a non-reinalin mask, with increased ventilatory work and productive cough at the verbal command. When performing RT-PCR, he obtained a positive result for the Coronavirus. RESULTS: The data collected through the analysis of medical records and clinical observation of the patient demonstrated that the physical therapy intervention, when using bronchial hygiene techniques, reexpansive maneuvers and active motor conducts, contributed to the clinical evolution of the patient, showing improvement in SpO2 and ventilatory discomfort. CONCLUSION: Physiotherapeutic interventions applied to this patient profile have shown positive results with regard to the improvement of gas exchange and respiratory discomfort, as well as appearing to influence the reduction in the risk of functional decline.

KEYWORDS: Physical Therapy Specialty. Respiratory Therapy. Coronavirus Infections. Pediatrics. 


\section{Introdução}

Em dezembro de 2019, uma nova classe de pneumonia viral, de etiologia desconhecida, foi notificada pela Comissão de Saúde da província de Hubei, em Wuhan, na China ${ }^{1}$. Posteriormente, o agente causador do vírus foi identificado pela Organização Mundial de saúde (OMS) como "novo coronavírus 2019" (2019 - nCoV)².

Inicialmente, eram escassos os casos desta infecção na população pediátrica, levantando à hipótese de que estes indivíduos não eram suscetíveis ao vírus. No entanto, após a manifestação de agregação familiar, novos casos gradativamente surgiram ${ }^{3}$. Apesar de se apresentarem em menor proporção, as crianças são tão propensas a infecções em geral quanto os adultos, tendo em vista que esta população é particularmente propícia a desenvolver distúrbios respiratórios, em decorrência de diversos fatores inter-relacionados que favorecem essa evolução, que vão desde peculiaridades anatômicas a características fisiológicas e imunológicas.

As crianças infectadas podem permanecer assintomáticas ou apresentar febre, tosse, fadiga, congestão nasal e alguns pacientes apresentaram sintomas gastrointestinais, incluindo desconforto abdominal, náusea, vômito e diarreia. A maioria das crianças infectadas tem manifestações clínicas leves, e os casos graves podem progredir rapidamente para choque séptico, acidose metabólica refratária, disfunção de coagulação e/ou síndrome de angústia respiratória aguda (SARA) ${ }^{3}$.

A partir das informações citadas acima, constata-se a eficácia da fisioterapia, que consiste numa especialidade terapêutica, que exerce papel fundamental na prevenção e tratamento de complicações pulmonares. Seu principal objetivo é melhorar a função respiratória dos pacientes, de modo a facilitar as trocas gasosas e adequar a relação ventilação-perfusão por meio de técnicas de higiene brônquica, ou seja, técnicas que facilitam o clearance mucociliar e a remoção de secreções, mantendo assim a permeabilidade das vias aéreas ${ }^{5}$. Tais técnicas reduzem o tempo de exposição à ventilação mecânica (VM) e o tempo de permanência na Unidade de Terapia Intensiva (UTI) ${ }^{6}$.

Diante do exposto, o objetivo deste estudo é descrever o quadro clínico de uma criança portadora de Cardiopatia Congênita com Coronavírus positivo e abordar a atuação fisioterapêutica pediátrica.

\section{Caso clínico}

O presente relato apresenta o caso da primeira paciente pediátrica do Instituto Couto Maia (ICOM) diagnosticada com o vírus. Trata-se de uma criança de 5 anos e 11 meses de idade, sexo feminino, admitida na Unidade de Terapia Intensiva Pediátrica (UTIP) do ICOM, no dia 18 de abril de 2020, às 20 h00.

Este estudo foi submetido ao Comitê de Ética e Pesquisa, sob o número CAEE 32864620.9.0000.0046 e aprovado o Parecer número 4.263.898, obedecendo aos princípios éticos dispostos na Resolução número 466/2012 e 510/2016 do Conselho Nacional de Saúde.

Trata-se de uma paciente independente funcional prévia, com diagnóstico antecedente de Cardiopatia Congênita dos tipos: Persistência do Canal Arterial (PCA) e Comunicação Interventricular (CIV). Para o PCA, houve correção prévia; para o CIV, permanece sem correção. Desde a última consulta, realizada em 2017, a paciente encontra-se sem acompanhamento com o cardiopediatra.

A paciente foi admitida na unidade com histórico de febre há 8 dias, rinorréia hialina e desconforto respiratório. Foi avaliada e realizou RT-PCR via Swab naso-orofagíngeo, que resultou positivo para o Coronavírus.

No exame clínico de entrada, a criança apresentava-se ativa, colaborativa e comunicativa ao manuseio, taquicárdica $145 \mathrm{bpm}$ (batimentos por minuto), taquipneica 35ipm (incursões por minuto), demonstrando saturação periférica de oxigênio ( $\mathrm{SpO} 2)$ de $85 \%$ em uso de máscara não reinalante, considerando que sua a $\mathrm{SpO} 2$ basal ao ar ambiente é $85 \%$ devido ao histórico das Cardiopatias subjacentes. Durante a avaliação, apresentou sinais de aumento de trabalho respiratório e a ausculta pulmonar revelou roncos difusos e crepitações precoces, sendo em seguida identificadas narinas pérvias e tosse produtiva ao comando verbal.

A tomografia computadorizada (TC) evidenciou um pequeno derrame pleural à direita, consolidação completa do lobo inferior esquerdo, broncogramas aéreos de permeio associados a consolidações focais e tênues, opacidades em "vidro-fosco" no lobo superior esquerdo e inferior direito, apresentando envolvimento do parênquima pulmonar entre $25-50 \%$. 
A hemogasometria arterial (HGA) indicou os seguintes dados: pH: 7,28, PCO2: 22,9, PO2: 61,2; HCO3: 10,6, BE: -13,4, SO2: 90\%, Lac: 3,64.

A paciente permaneceu internada na UTIP por 10 dias e durante este período permaneceu em leito de isolamento com pressão negativa e estava sob acompanhamento da equipe de fisioterapia pediátrica, que realizou atendimento quatro vezes ao dia em todo o período de hospitalização.

No primeiro dia de internação, houve piora do estado geral com hipoatividade, hipoglicemia (HGT=50 mg/ dl) e crise convulsiva, sendo administrados diazepam e glicose, conforme descrito na ficha de parada pela equipe de enfermagem.

No segundo dia de internação, a paciente demonstrou estabilidade clínica e realizou um Ecocardiograma Funcional que evidenciou fração de ejeção em 35\%, dimensões de ventrículos aumentadas com espessamento de paredes ventriculares, veia cava sem turgência e com boa distensibilidade.

A avaliação fisioterapêutica do sistema pulmonar detectou limitações caracterizadas pelo aumento de carga resistiva por componente secretivo, com impacto em oxigenação. A partir disso, foram iniciadas as condutas de forma lúdica, objetivando promover a compreensão e a aceitação do tratamento necessário, bem como reduzir o estresse inerente à hospitalização.

Diante deste quadro, foi mantida a oxigenoterapia de alto fluxo via máscara não reinalante, que resultou na elevação da SpO2 (89\%). Além disso, foi identificado o risco de declínio funcional secundário ao período de internamento, este quesito foi avaliado por meio da Functional Status Scale (FSS) destinada a população pediátrica. Nesta análise, obteve-se a pontuação 7 desde o momento da admissão.

Ademais, foram implementadas as seguintes condutas: Monitorização cardiorrespiratória, expiração lenta e prolongada (ELPr), estímulo verbal a tosse, desmame de oxigênio para máscara de Venturi considerando uma fração inspirada de oxigênio $(\mathrm{FiO} 2)$ de $50 \%$ e fluxo $15 \mathrm{~L} / \mathrm{m}$, sedestação no leito e alinhamento biomecânico.
Posteriormente, no quinto dia de internação, o quadro da paciente permaneceu estável, demonstrando curva de melhora nas limitações identificadas previamente, em que foram observados os seguintes parâmetros: frequência cardíaca: 114 bpm, frequência respiratória: 25 ipm e SpO2: 89\% em oxigenoterapia de alto fluxo via máscara de Venturi com $\mathrm{FiO} 2$ de $31 \%$ e fluxo de $8 \mathrm{~L} / \mathrm{m}$. Baseado nas informações coletadas, foram adotadas como condutas: Aumento do fluxo expiratório lento (AFEL), padrões ventilatórios reexpansivos, cinesioterapia, estímulo verbal a tosse, mobilizações no leito, alinhamento biomecânico e desmame de oxigênio para cateter nasal ofertando o fluxo de $3 \mathrm{~L} / \mathrm{m}$.

No décimo dia de internação, a paciente demonstrava melhora significativa em ausculta pulmonar apresentando: murmúrio ventilatório presente sem ruídos adventícios, narinas pérvias em uso de oxigenoterapia de baixo fluxo via cateter nasal tipo óculos, sendo ofertado o fluxo de 3L/m, apresentando SpO2 96\%. Neste dia, também foi observado que a paciente não apresentou declínio funcional secundário ao período de internamento, sendo identificada a mesma pontuação obtida no momento da admissão (7 pontos). No entanto, necessitou de assistência com cardiopediatra, sendo transferida para outro hospital devido à ausência desta especialidade na presente unidade, onde realizou a continuação do tratamento cardíaco.

\section{Discussão}

Apesar de apresentar-se em menor frequência, os casos graves da COVID-19 podem também afetar a população pediátrica, sendo bem descrito em um estudo Coorte realizado na China, o qual contou com uma amostra de 2.143 crianças, em que $34,1 \%$ deste público são casos confirmados da doença ${ }^{7}$.

$\mathrm{Na}$ Coorte acima citada, relata-se que cerca de $0,4 \%$ dos pacientes confirmados foram considerados casos graves, onde categorizaram os quadros, levando em conta as características clínicas, achados laboratoriais e radiológicos, descrevendo os casos graves como aqueles em que os pacientes apresentassem: pneumonia, febre, tosse, $\mathrm{SpO} 2<92 \%$ e desconforto respiratório $?$. 
Corroborando com este estudo, o presente relato descreve que a paciente foi admitida com o histórico de febre há 8 dias e desconforto respiratório, bem como rinorreia hialina e taquicardia. Durante a avaliação fisioterapêutica, também se observou tosse produtiva ao comando verbal e alterações na impedância pulmonar por componente secretivo com impacto na oxigenação sendo verificada a $\mathrm{SpO} 2$ de $85 \%$ em uso de máscara não reinalante.

Além disso, a paciente apresentou achados tomográficos com características semelhantes às encontradas na literatura relacionadas aos pacientes com diagnóstico de COVID-19, sendo evidenciados a presença de broncogramas associados a consolidações focais, consolidação completa do lobo inferior esquerdo, opacidades em "vidro fosco" e derrame pleural.

Os referidos achados tomográficos estão de acordo com os resultados descritos no estudo realizado por Ramos et al.8, onde ratificam que dentre os principais achados tomográficos observados em crianças infectadas pelo vírus encontram-se: opacidades irregulares em "vidro fosco" e presença de condensações, podendo ser uni ou bilaterais, variando de acordo com a progressão da doença. Entretanto, os autores sinalizam que estes resultados, quando analisados isoladamente, não são suficientes para diagnosticar o caso, já que outras infecções podem apresentar achados semeIhantes, além da possibilidade de haver coinfecções ${ }^{\text {. }}$

Frente às condições em que pacientes pediátricos cursam com quadros de infecção respiratória, Pinto et al.9 afirmam que a fisioterapia pediátrica no âmbito hospitalar terá como principais objetivos: minimizar os efeitos das complicações pulmonares e meIhorar a função respiratória das crianças. Além disso, ainda neste estudo, foi evidenciado que no cenário descrito, as condutas fisioterapêuticas aplicadas, considerando os objetivos mencionados, demonstraram resultados estatisticamente significativos na redução dos sinais de desconforto respiratório, avaliado por meio do Boletim de Silverman-Andersen.

Neste relato, a paciente abordada cursou com um quadro de desconforto ventilatório secundário as alterações no sistema pulmonar citadas anteriormente. Neste contexto, as técnicas fisioterapêuticas realizadas foram definidas considerando objetivos semelhantes aos citados no estudo de Pinto et al. $\stackrel{9}{9}$ e, desta forma, foi traçado um plano terapêutico dispondo condutas que incluem desde estratégias de higiene brônquica a condutas motoras ativas.

No que se refere às técnicas de higiene brônquica, Gomes et al. 10 realizaram um Ensaio Clínico Randomizado (ECR) em que avaliaram a eficácia de técnicas semelhantes as citadas neste relato em lactentes com o quadro de bronquiolite viral aguda (BVA). Neste ECR, os resultados evidenciaram que as manobras desobstrutivas, bem como o estímulo a tosse, melhoram a curto prazo a pontuação obtida pelo escore de Wang, que considera como parâmetros: retrações, frequência respiratória, sibilância e estado geral.

Quanto às técnicas reexpansivas, Tomich et al. ${ }^{11}$ afirmam que tais manobras são capazes de aumentar a capacidade residual e garantir maior estabilidade alveolar, estando de acordo com os objetivos elegidos para determinação das manobras terapêuticas utilizadas neste relato.

Conforme os dados descritos nos estudos realizados por Tomich et al..$^{11}$ e Gomes et al. ${ }^{10}$, o presente caso demonstra que poucos dias após iniciar o plano terapêutico, a paciente apresentou melhora relacionada ao desconforto ventilatório e hipoxemia, traduzidos pela redução da litragem de oxigênio ofertada e elevação progressiva da SpO2, bem como a normalização dos demais marcadores funcionais do sistema cardiorrespiratório.

De forma semelhante, as condutas motoras mencionadas no presente estudo foram aplicadas com base nos dados dispostos na literatura vigente, onde são relatados os benefícios associados à realização de condutas ativas e passivas com crianças hospitalizadas, demonstrando resultados satisfatórios no que se refere a redução do risco de declínio funcional ${ }^{12}$.

Entre os instrumentos possíveis para avaliar a funcionalidade infantil, destaca-se a FSS para utilização em crianças hospitalizadas. Esta escala é composta por seis domínios (estado mental, funcionamento sensorial, comunicação, funcionamento motor, alimentação e estado respiratório), e cada domínio pode ser pontuado no intervalo compreendido entre 1 e 5 pontos, 
sendo que 1 ponto corresponde ao desfecho "normal" e 5 pontos significa "disfunção muito severa". A pontuação global varia entre 6 e 30 pontos, em que se classifica "adequado" as pontuações entre 6 e $7^{1 \frac{13}{}}$.

No ECR realizado por Rocha et al..$^{12}$ em uma UTIP, que analisou os efeitos da mobilização precoce em crianças com idades entre um e cinco anos, com diagnóstico de pneumonia associada a ventilação mecânica, salientou que condutas como sedestação no leito, ortostase, alongamento e mobilizações articulares ativas e passivas, durante o período de internação, previnem comprometimentos físicos e neuropsicológicos, além de melhorar a modulação autonômica da frequência cardíaca.

Foi observado neste relato que a abordagem fisioterapêutica contou com condutas motoras desde o primeiro contato e, corroborando com o que foi descrito no ECR supracitado, a paciente não apresentou declínio funcional desde a admissão até a sua transferência para outra unidade hospitalar, sendo pontuado de acordo com a FSS o total de 7 pontos em todos os momentos avaliados.

Em relação à função cardíaca, Su et al. ${ }^{14}$ realizaram um estudo retrospectivo em que foi feita a análise de achados clínicos, laboratoriais e radiológicos, que incluíram nove crianças positivadas com o vírus e suas respectivas famílias. Observou-se nos exames laboratoriais de seis crianças e dois adultos a elevação de enzimas cardíacas, indicando que o vírus também pode apresentar repercussões neste sistema. Assim sendo, enfatiza-se a necessidade de monitorização contínua na assistência dos pacientes positivados e, de forma mais intensa, àqueles que apresentam disfunções prévias do sistema cardiovascular.

Em conformidade com Su et al. ${ }^{14}$, Eastin et al. ${ }^{7}$ afirmam em sua Coorte que dentre os casos graves, aqueles que precisarão de hospitalização provavelmente acontecerão em crianças que apresentam histórico de doenças subjacentes e citam as alterações cardiovasculares. Faz-se necessário ressaltar que a paciente em questão neste relato cursa com um quadro de CIV não corrigida, sem acompanhamento há 3 anos, e apresenta repercussões hemodinâmicas onde é permitida a tolerância da $\mathrm{SpO} 2>85 \%$, além de evidenciar uma fração de ejeção de 35\%, demandando desta forma de assistência especializada e por esta razão, foi encaminhada para outra unidade de atendimento.
Dentre os profissionais envolvidos no processo de reabilitação dos pacientes portadores do COVID-19, a atuação fisioterapêutica torna-se essencial, não por tratar diretamente a doença, mas por mostrar-se capaz de prevenir e reabilitar deficiências e limitações funcionais causadas pelo vírus ${ }^{14}$.

Este estudo apresenta como limitação o fato de relatar um único caso, sendo possível apenas retratar o caso clínico e suas repercussões. No entanto, os resultados encontrados podem nortear intervenções fisioterapêuticas em pacientes que apresentem condições semelhantes, em concordância com a literatura apresentada. Porém, destaca-se a necessidade de realizar novos estudos nesta população, com maior robustez metodológica, para evidenciar os efeitos da atuação fisioterapêutica.

\section{Conclusão}

Nota-se que o quadro apresentado pela paciente relatada, condiz com os dados já descritos na literatura em questão. Além disso, observou-se que as intervenções fisioterapêuticas aplicadas a este perfil de paciente, demonstraram resultados positivos no que diz respeito à melhora das trocas gasosas e desconforto respiratório, bem como parece influenciar a redução do risco de declínio funcional.

\section{Contribuições das autoras}

Oliveira JS participou da concepção, delineamento, busca e análise dos dados da pesquisa, interpretação dos resultados e redação do artigo científico. Veiga IN participou da concepção, delineamento, análise dos dados da pesquisa, interpretação dos resultados e redação do artigo científico. Mota CS participou da busca de dados para a pesquisa, interpretação dos resultados e escrita do artigo.

\section{Conflitos de interesses}

Nenhum conflito financeiro, legal ou político envolvendo terceiros (governo, empresas e fundações privadas, etc.) foi declarado para nenhum aspecto do trabalho submetido (incluindo, mas não se limitando a subvenções e financiamentos, participação em conselho consultivo, desenho de estudo, preparação de manuscrito, análise estatística, etc.). 


\section{Referências}

1. Awadasseid A, Wu Y, Tanaka Y, Zhang W. Initial success in the identification and management of the coronavirus disease 2019 (COVID-19) indicates human-to-human transmission in Wuhan, China. Int J Biol Sci. 2020;16(11):1846-60. https://doi.org/10.7150/ ijbs.45018

2. World Health Organization. WHO Coronavirus Disease (COVID-19) Dashboard [Internet]. 2020.[citado 2020 jul. 14]. Disponível em: https://covid19.who.int/

3. Xia W, Shao J, Guo Y, Peng X, Li Z, Hu D. Clinical and features in pediatric patients with COVID-19 infection: Different points from adults. Pediatric Pulmonology. 2020;55(5):1169-74. https://doi. org/10.1002/ppul.24718

4. Sociedade Brasileira de Pediatria (SBP). Insuficiência Respiratória Aguda [Internet]. Departamento Cientifico de Terapia Intensiva. 2017. 7 p. Disponível em: https://www.sbp.com.br/ fileadmin/user_upload/Terapia___Insuficiencia_Respiratoria_ Aguda.pdf

5. Oliveira EAR, Gomes ELFD. Evidência Cientifica das técnicas atuais e convencionais de fisioterapia respiratória em pediatria. Fisioterapia Brasil. 2016;17(1):88-97. http://dx.doi.org/10.33233/ fb.v17i1.30

6. Reis GR, Rossone APF, Santos TPG, Neves RS. A importância da mobilização precoce na redução de custos e na melhoria da qualidade das Unidades de Terapia Intensiva. Rev. Aten. Saúde [Internet]. 2018;16(56):94-100. Disponível em: https://seer.uscs. edu.br/index.php/revista_ciencias_saude/article/view/4922/pdf

7. Eastin C, Eastin T. Epidemiological characteristics of 2143 pediatric patients with 2019 coronavirus disease in China: Dong Y, Mo X, Hu Y, et al. Pediatrics. J Emerg Med. 2020;58(4):712-3. https://doi.org/10.1016/j.jemermed.2020.04.006

8. Ramos RT, Silva DCC, Araújo GB, Riedi CA, Ibiapina CC, Bezerra PGM, et al. Aspectos respiratórios da COVID-19 na infância: o que o pediatra precisa saber?. Residência Pediátrica. 2020;10(2):1-15. http://dx.doi.org/10.25060/residpediatr-2020.v10n2-349
9. Pinto $B F$, Araújo $P Q$, Amaral JDF. Atuação da fisioterapia no esforço respiratório em crianças hospitalizadas com infecção respiratória aguda: um estudo comparativo. Fisioterapia Brasil. 2017;18(2):140-7. http://dx.doi.org/10.33233/fb.v18i2.791

10. Gomes ELFD, Postiaux G, Medeiros DRL, Monteiro KKDS, Sampaio LMM, Costa D. A fisioterapia respiratória é eficaz na redução de escore clínico na bronquiolite: ensaio controlado randomizado. 2012;16(3):241-7. https://doi.org/10.1590/S1413$\underline{35552012005000018}$

11. Tomich GM, França DC, Diniz MTC, Britto RR, Sampaio F, Pereira VF. Efeitos dos exercícios respiratórios no padrão respiratório e movimento toracoabdominal após gastroplastia. J Bras Pneumol. 2010;36(2):197-204. https://doi.org/10.1590/S1806$\underline{37132010000200007}$

12. Rocha GQ, Santos JB, Oliveira MHL, Avila PES, Rocha RSB. Efeitos da mobilização precoce em crianças com pneumonia associada à ventilação mecânica: efeitos sobre variáveis não lineares da variabilidade da frequência cardíaca. R. bras. Ci. e Mov. 2019;27(3):93-9. http://dx.doi.org/10.31501/rbcm. v27i3.10051

13. Bastos VCS, Carneiro AAL, Barbosa MSR, Andrade LB. Versão Brasileira da Functional Status Scale pediátrica: tradução e adaptação transcultural. Rev Bras Ter Intensiva. 2018;30(3):301-7. Citado em: PMID: 30183976

14. Su L, Ma X,Yu H, Zhang Z, Bian P, Han Y, et al. The different clinical characteristics of corona virus disease cases between children and their families in China - the character of children with COVID-19. Emerging Microbes \& Infections. 2020;9(1):707-13. https://doi.org/10.1080/22221751.2020.1744483

15. Bispo Júnior JP. Fisioterapia e saúde coletiva: desafios e novas responsabilidades profissionais. Ciênc. Saúde Coletiva. 2010;15(1):1627-36. http://dx.doi.org/10.1590/S141381232010000700074 